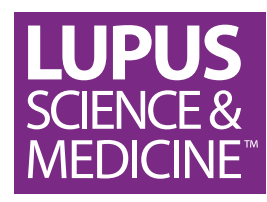

\title{
Central nervous system infections in patients with systemic lupus erythematosus: a systematic review and meta-analysis
}

\author{
Kasra Molooghi (D) , ${ }^{1}$ Fereshte Sheybani (D) , ${ }^{1}$ Hamidreza Naderi, ${ }^{1}$ Zahra Mirfeizi, ${ }^{2}$ \\ Negar Morovatdar, ${ }^{3}$ Ashkan Baradaran ${ }^{1}$
}

To cite: Molooghi K, Sheybani F, Naderi $\mathrm{H}$, et al. Central nervous system infections in patients with systemic lupus erythematosus: a systematic review and meta-analysis. Lupus Science \& Medicine 2022;9:e000560. doi:10.1136/ lupus-2021-000560

- Additional supplemental material is published online only. To view, please visit the journal online (http://dx.doi.org/10. 1136/lupus-2021-000560).

Received 13 August 2021 Accepted 9 December 2021

Check for updates

(C) Author(s) (or their employer(s)) 2022. Re-use permitted under CC BY-NC. No commercial re-use. See rights and permissions. Published by BMJ.

${ }^{1}$ Department of Infectious Diseases and Tropical Medicine, Faculty of Medicine, Mashhad University of Medical Sciences, Mashhad, Iran

${ }^{2}$ Rheumatic Diseases Research Center, Mashhad University of Medical Sciences, Mashhad, Iran ${ }^{3}$ Clinical Research Unit, Faculty of Medicine, Mashhad University of Medical Sciences, Mashhad, Iran

Correspondence to Dr Fereshte Sheybani; fereshtesheybani@gmail.com

\section{ABSTRACT}

We aimed to conduct a systematic review and metaanalysis of studies on central nervous system (CNS) infections in patients with SLE, in order to describe their clinical and microbiological characteristics, and outcomes. A systematic search of PubMed/Medline and Embase electronic databases was performed (March 2021) to identify all published studies on CNS infections and their characteristics in patients with SLE. A random-effects model was adopted and findings were reported with $95 \%$ Cl. Overall, 6 studies involving 17751 patients with SLE and 209 SLE cases with CNS infection were included in our meta-analysis. The frequency rate of CNS infections in patients with SLE was 0.012 (95\% Cl: 0.008 to 0.018$)$. Meningitis was the most common clinical syndrome (93.5\%, $\mathrm{n}=109 / 114,95 \% \mathrm{Cl}: 82.6 \%$ to $97.8 \%)$ and Cryptococcus neoformans $(35.9 \%, \mathrm{n}=55,95 \% \mathrm{Cl}: 27.2 \%$ to $45.7 \%$ ) and Mycobacterium tuberculosis (27.1\%, $\mathrm{n}=43,95 \% \mathrm{Cl}: 14.6 \%$ to $44.8 \%$ ) were the most common causative pathogens. Our patient-pool showed a mean SLE Disease Activity Index (SLEDAl) score of 7.9 (95\% Cl: 6.1 to 9.6), while $92.4 \%(\mathrm{n}=72 / 76,95 \% \mathrm{Cl}: 83.0 \%$ to $96.8 \%$ ) of cases were on oral systemic corticosteroids, with a prednisone equivalent mean daily dose of $30.9 \mathrm{mg} /$ day ( $95 \% \mathrm{Cl}: 18.0$ to 43.7$)$. Our meta-analysis revealed a mortality rate of $29.0 \%$ (95\% Cl: $15.0 \%$ to $48.6 \%)$. Clinicians should maintain a high index of suspicion for cryptococcal and tuberculosis (TB) meningitis in patients with SLE with suspected CNS infection, particularly in those with higher SLEDAl and on higher doses of systemic corticosteroids. In conclusion, initiation of empiric antituberculous treatment for patients with SLE who are highly suspected to have CNS TB is warranted while awaiting the results of diagnostic tests. Antifungals might also be potentially useful empirically in patients with SLE who are suspected to have fungal CNS infections. However, with respect to side effects such as toxicity and high cost of antifungals, decision regarding early antifungal therapy should be guided by early and less time-consuming fungal diagnostic tests.

\section{INTRODUCTION}

SLE is a complex autoimmune disorder characterised by chronic systemic inflammation
Key messages

What is already known about this subject?

- Major infections including those of the central nervous system (CNS) account for significant morbidity and mortality in patients with SLE.

What does this study add?

- Our study provides relevant data for helping clinicians with the diagnostic and treatment approach to CNS infections in patients with SLE.

How might this impact on clinical practice or future developments?

- Clinicians should maintain a high index of suspicion for cryptococcal and TB meningitis in patients with SLE with suspected CNS infection, particularly in those with higher SLE Disease Activity Index and on higher doses of systemic corticosteroids.

- Antifungals might be potentially useful empirically in patients with SLE who are suspected to have fungal CNS infections.

- However, with respect to side effects such as toxicity and high cost of antifungals, decision regarding early antifungal therapy should be guided by early and less time-consuming fungal diagnostic tests.

- Empiric antituberculous treatment is warranted for patients with SLE who are highly suspected to have CNS TB while awaiting the results of diagnostic tests.

that can affect almost any organ. ${ }^{12}$ It is associated with a two-fold to six-fold increase in the risk of infection and a 12-fold increase in the rate of hospitalisation due to serious infectious complications compared with the general population. ${ }^{3-5}$ Infections account for $13 \%-37 \%$ of hospitalisations and $15.1 \%-$ $37.5 \%$ of deaths in major SLE cohorts. ${ }^{6-20}$ Patients with SLE have a five times higher risk of death due to infections than the general population. ${ }^{12}$ Factors associated with impaired immune response in patients with SLE include $\mathrm{T}$ cell and natural killer cell dysfunction as well as complement deficiencies. ${ }^{21}$ 
Furthermore, immune-modulating effects of glucocorticoids, disease-modifying antirheumatic drugs, novel biological agents and other immunosuppressive agents such as cyclophosphamide (CYC), azathioprine (AZA), mycophenolate mofetil (MMF) and methotrexate (MTX) can lead to a more intense compromise in their immune function. ${ }^{22}$

Pleuropulmonary, urinary tract and skin and soft tissue infections are the most commonly reported infectious complications in patients with SLE. ${ }^{13-1623}$ Central nervous system (CNS) infections, although less frequent, are associated with significant morbidity and mortality in immunocompromised patients with SLE. ${ }^{24}{ }^{25}$ They can mimic the symptoms of neuropsychiatric lupus or a lupus flare; however, require an entirely different management. ${ }^{26-28}$ Early diagnosis and appropriate treatment of patients with SLE with CNS infections are critical and any delays can be associated with a catastrophic outcome. ${ }^{2728}$

Information about the clinical characteristics and outcome of CNS infections in patients with SLE are limited. Here, we conducted a descriptive systematic review and meta-analysis on observational studies that investigated CNS infections in patients with SLE, in order to report the frequency rate of CNS infections and their demographic features, clinical and microbiological characteristics and outcomes, such as morbidity and mortality.

\section{METHODS AND MATERIALS}

\section{Search strategy}

This meta-analysis was registered in PROSPERO (UK Centre for Reviews and Dissemination, University of York, York, UK, ID number CRD42020204986) and was conducted according to Preferred Reporting Items for Systematic Reviews and Meta-Analyses (PRISMA) and the Meta-analysis of Observational Studies in Epidemiology guidelines. ${ }^{29} 30$ We systematically searched PubMed/ Medline and Embase electronic databases on 1 March 2021. We used "Systemic Lupus Erythematosus" in combination with phrases such as meningitis, Central Nervous System Infection, etc, as Medical Subject Headings and text words, to identify studies on CNS infections in patients with SLE. We imposed no restrictions regarding time of publication, language, country of study or publication type to the initial search. In addition, we manually searched the references of included manuscripts for any potentially eligible articles. Full search strategy is available in online supplemental data S1.

\section{Study selection}

We included observational studies that investigated CNS infections and their characteristics in patients with SLE. Two reviewers (KM and FS) independently evaluated the titles and abstracts for eligibility. $\mathrm{KM}$ and $\mathrm{AB}$ retrieved relevant full-text manuscripts and selected the studies that fulfilled the eligibility criteria. Any discrepancies between results were resolved by consensus among authors. We excluded case reports, review articles, conference abstracts and posters, while eliminating non-English articles. Furthermore, we omitted the abstracts that did not have an obtainable full manuscript and removed the studies that only reported one specific subtype of CNS infections (eg, only hospital-acquired infections, opportunistic infections, etc), populations (eg, only mortality cases, juvenile/childhood-onset subjects with SLE or febrile patients) or pathogens (such as only Mycobacterium tuberculosis, Cryptococcus neoformans, etc). When we came across two studies with partially duplicated data sets, we opted for the study that covered a larger duration and population. Full selection criteria is available in online supplemental data S2.

Two investigators ( $\mathrm{KM}$ and $\mathrm{AB}$ ) independently collected information regarding country and year of publication, SLE population size, study design and duration. In addition, data on frequency and characteristics of the patients with SLE with CNS infections such as gender, age, SLE duration, comorbidities, glucocorticoid use and dose, use of other immunosuppressive agents, clinical syndromes, symptoms on admission, causative pathogens, the interval between the diagnosis of SLE and CNS infection, time interval from the onset of neurological symptoms to the diagnosis of CNS infections, systemic or neurological sequelae, relapse and mortality were recorded, if available in the manuscripts. In order to evaluate disease activity and cumulative damage, we recorded SLE Disease Activity Index (SLEDAI) and Systemic Lupus International Collaborating Clinics/American College of Rheumatology (ACR) Damage Index, respectively, if provided in the articles. ${ }^{31}{ }^{32}$ Uncertainties were resolved by the help of a third reviewer (FS). Finally, we used the NewcastleOttawa Scale $(\mathrm{NOS})^{33}$ for assessing the methodological quality of the selected observational studies (online supplemental table $\mathrm{S} 1$ ).

\section{Data analysis}

Comprehensive Meta-Analysis Software was used for meta-analysis. Heterogeneity between studies was assessed using the Cochran's $Q$ test and $\mathrm{I}^{2}$ statistic. Heterogeneity was considered statistically significant if $p$ value was $<0.05$ for Cochran's Q-statistics. I ${ }^{2}$ values of $<40 \%$ and 40 to $70 \%$ showed minimal and moderate heterogeneity, respectively, while a value of $>70 \%$ indicated substantial heterogeneity. We used the random-effects model with the weighting of the studies. OR, mean difference and standardised mean difference along with 95\% CI were applied to the analysis. As the number of available studies were below 10, we did not perform meta-regression analysis due to its low reliability. In order to evaluate publication bias, funnel plots were constructed to visualise possible asymmetry when three or more studies were available. ${ }^{34}$ However, according to Sterne $e t a l^{35}$ when there are fewer than 10 studies in the meta-analysis, test power is usually too low to distinguish chance from real asymmetry or the implications of heterogeneity from publication bias; consequently, no further mathematical tests were performed. 


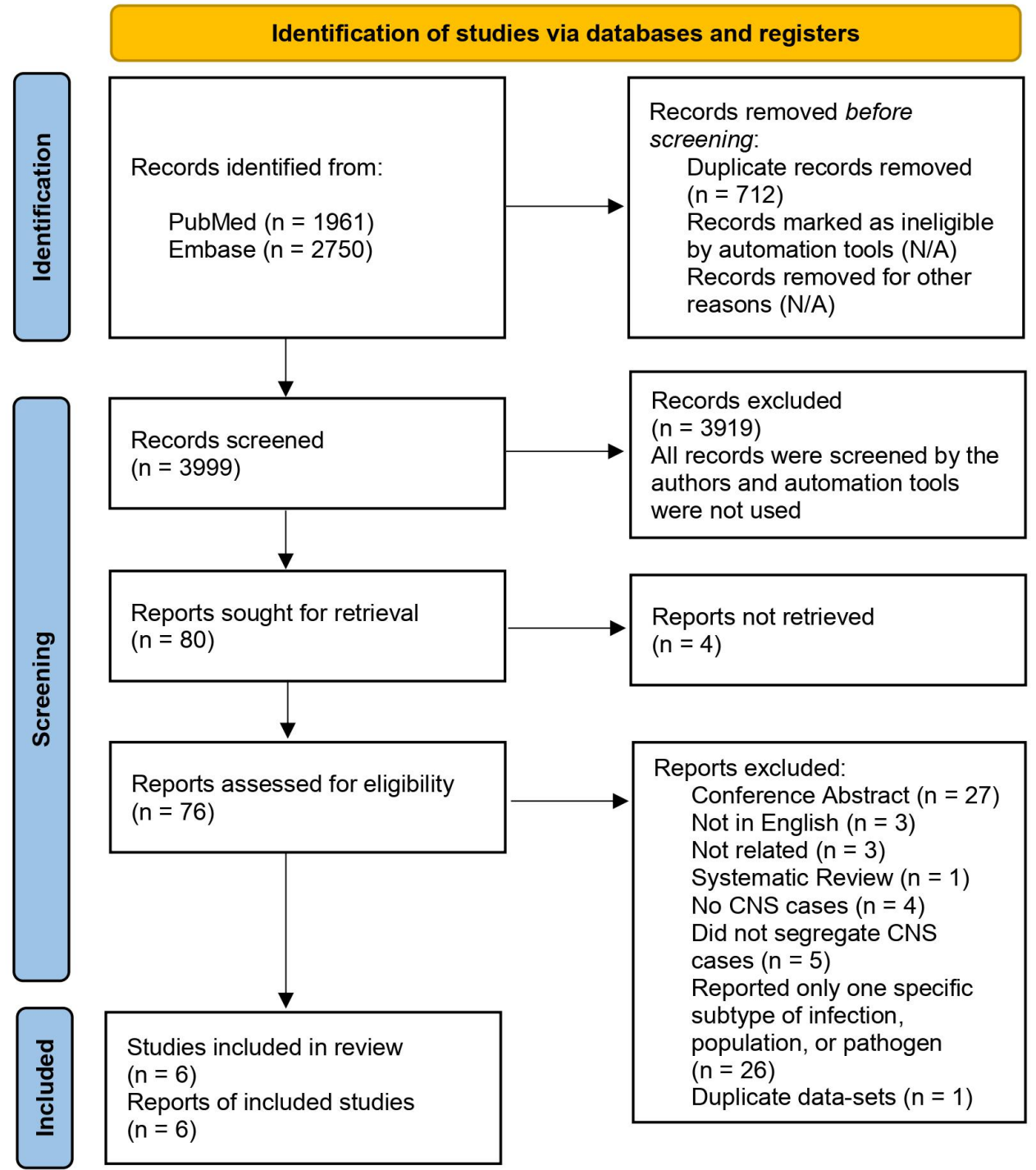

Figure 1 Preferred Reporting Items for Systematic Reviews and Meta-Analyses flow diagram. CNS, central nervous system; N/A, not available. Adapted from Page et al. ${ }^{29}$ For more information, visit: http://www. prisma-statement.org/.

\section{RESULTS}

Study characteristics

We identified 3999 citations through the literature search and excluded 3919 irrelevant titles and abstracts after initial screening. After evaluating the full texts of 80 potentially relevant manuscripts for eligibility, 6 articles were included in the meta-analysis ${ }^{36-41}$ (figure 1). Reference lists of the selected studies were then manually reviewed; however, no additional manuscripts were added to the final analysis. We selected Jiang et al in favour of $\mathrm{Xu} e t a t^{2}$ due to covering a larger duration and population. Two studies (Yang et al and Jiang et al) acquired a full score on the NOS quality assessment checklist while the others received 6/9, due to not providing a control group for comparing the characteristics of patients with SLE with or without CNS infections. The selected studies were predominantly from Asian regions such as China, Korea, The Philippines and Taiwan, with only one study (Baizabal-Carvallo et al) from northern America (Mexico). All studies have reviewed the patient records/charts of an SLE database/cohort retrospectively for at least 10 years, and five studies were single-centre, whereas only Kim et al had a multicentre database. Overall, the analysis involved 17751 patients with SLE, who fulfilled the ACR criteria. ${ }^{43}$ In order to diagnose CNS infections, all studies employed clinical criteria as well as microbiological test results with the help of a multidisciplinary expert team; however, two studies (Hung et al and Yang et al) only reported definite infections where microorganisms were isolated by cultures, stains or PCR, and two studies (Baizabal-Carvallo et al and Kim et al) reported negative or unidentified agents in a separate group called aseptic/non-infectious meningitis, while two studies (Vargas et al and Jiang et al) reported all their data in a single group, namely CNS infections. In addition, cases with neuropsychiatric syndromes, possibly produced by SLE activity which could explain the manifestations, were excluded from the original studies, except for aseptic/non-infectious meningitis 
Table 1 Patient characteristics of the included studies on patients with SLE with CNS infection

\begin{tabular}{|c|c|c|c|c|c|c|c|c|c|}
\hline Study & \multicolumn{2}{|c|}{ Publication year } & $\begin{array}{l}\text { Study } \\
\text { period } \\
\text { (years) }\end{array}$ & Country & Study design & \multicolumn{2}{|l|}{ Gender } & \multicolumn{2}{|c|}{$\begin{array}{l}\text { Age at the time } \\
\text { of CNS infection } \\
\text { diagnosis } \\
\text { (years) }\end{array}$} \\
\hline $\begin{array}{l}\text { Baizabal- } \\
\text { Carvallo et } \\
a l^{36}\end{array}$ & \multicolumn{2}{|l|}{2009} & 19 & Mexico & Retrospective & 24 & 1 & 27.5 & 7.4 \\
\hline Jiang et $a l^{38}$ & \multicolumn{2}{|l|}{2019} & 26 & China & Retrospective & 81 & 14 & 34.6 & 13.7 \\
\hline Kim et $\left.a\right|^{39}$ & \multicolumn{2}{|l|}{2011} & 12 & Korea & Retrospective & 10 & 1 & 34.6 & 3.8 \\
\hline $\begin{array}{l}\text { Vargas et } \\
\left.\mathrm{a}\right|^{40}\end{array}$ & \multicolumn{2}{|l|}{2009} & 10 & Philippines & Retrospective & 22 & 1 & 30.9 & 11.9 \\
\hline \multirow{2}{*}{$\begin{array}{l}\text { Study } \\
\text { Baizabal- } \\
\text { Carvallo et } \\
\text { a/ }\end{array}$} & $\mathbf{N}$ & $\mathbf{N}$ & \multicolumn{2}{|c|}{ Mean $\quad$ SD } & Mean & SD & Mean & \multicolumn{2}{|r|}{ SD } \\
\hline & 1411 & 25 & 10.6 & 7.8 & 2.24 & 1.78 & 57.8 & & 37 \\
\hline Hung et $a l^{37}$ & 3165 & 17 & 5.9 & 3 & -- & -- & 25.9 & & 43.6 \\
\hline Jiang et $\left.a\right|^{38}$ & 8491 & 95 & 8 & 7.3 & 1.03 & 1.04 & -- & & -- \\
\hline Kim et $a l^{39}$ & 1420 & 11 & 11 & 1.9 & -- & -- & 64.7 & & 21.9 \\
\hline
\end{tabular}

CNS, Central nervous system; SLE, Systemic lupus erythematosus; SLEDAI, SLE Disease Activity Index; SLICC/ACR, Systemic Lupus International Collaborating Clinics/American College of Rheumatology.

cases in the study by Kim et al that were excluded from our patient pool (full criteria used by each study for the diagnosis of CNS infection is available in online supplemental data S3). The meta-analysis included 209 SLE cases with CNS infection, with a female:male ratio of 8.5:1 (187 female patients, $89.5 \%$ ) and a mean age of 32.2 years (95\% CI: 29.5 to $35.0, \mathrm{I}^{2} 73.6 \%$ ). The frequency rate of CNS infections in patients with SLE was 0.012 (95\% CI: 0.008 to $0.018, \mathrm{I}^{2} 84.8 \%$ ), while mean SLEDAI score was 7.9 (95\% CI: 6.1 to $9.6, \mathrm{I}^{2}$ $74.5 \%)$. The funnel plot for frequency rate was asymmetric (online supplemental figure S1), probably due to substantial heterogeneity. Details and characteristics of the SLE populations with CNS infection are available in table 1, figure 2 and online supplemental figure S2.

\section{Clinical syndromes}

Five studies reported 109 patients with a primary diagnosis of meningitis $(93.5 \%, \mathrm{n}=109 / 114,95 \% \mathrm{CI}$ : $82.6 \%$ to $97.8 \%, \mathrm{I}^{2} 30.1 \%$ ) and 5 cases with primary brain abscess, whereas Jiang et al did not report the clinical syndromes of their patients (table 2 and online supplemental figure S2). In addition, brain CT or MRI detected five additional cases of brain abscess among those with meningitis $(10.7 \%$, total of $10 / 114,95 \%$ CI: $5.8 \%$ to $\left.18.8 \%, \mathrm{I}^{2}<0.1 \%\right)$. None of the studies reported clinical syndromes other than meningitis or brain abscess (no cases of encephalitis, subdural or epidural empyema, septic thrombophlebitis, infectious myelitis

\section{CNS Infection Frequency Rate}

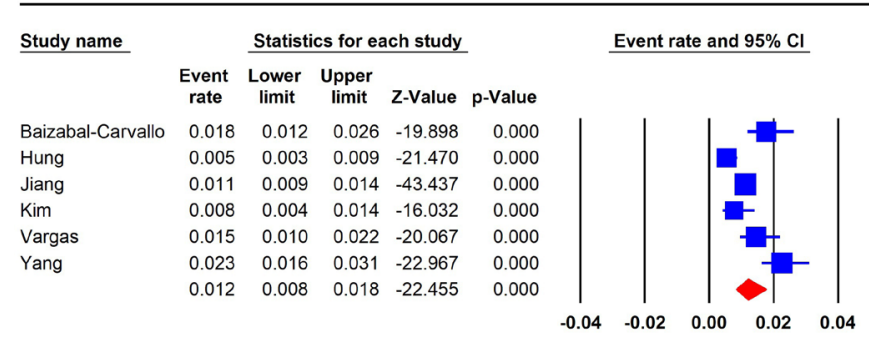

Figure 2 Forest plot showing the meta-analysis results of central nervous system (CNS) infection frequency rate in patients with SLE. 
Table 2 Medications, syndromes, symptoms, pathogens, mortality and morbidities of patients with SLE with CNS infection CNS infection syndromes (n) Symptoms on admission (n)

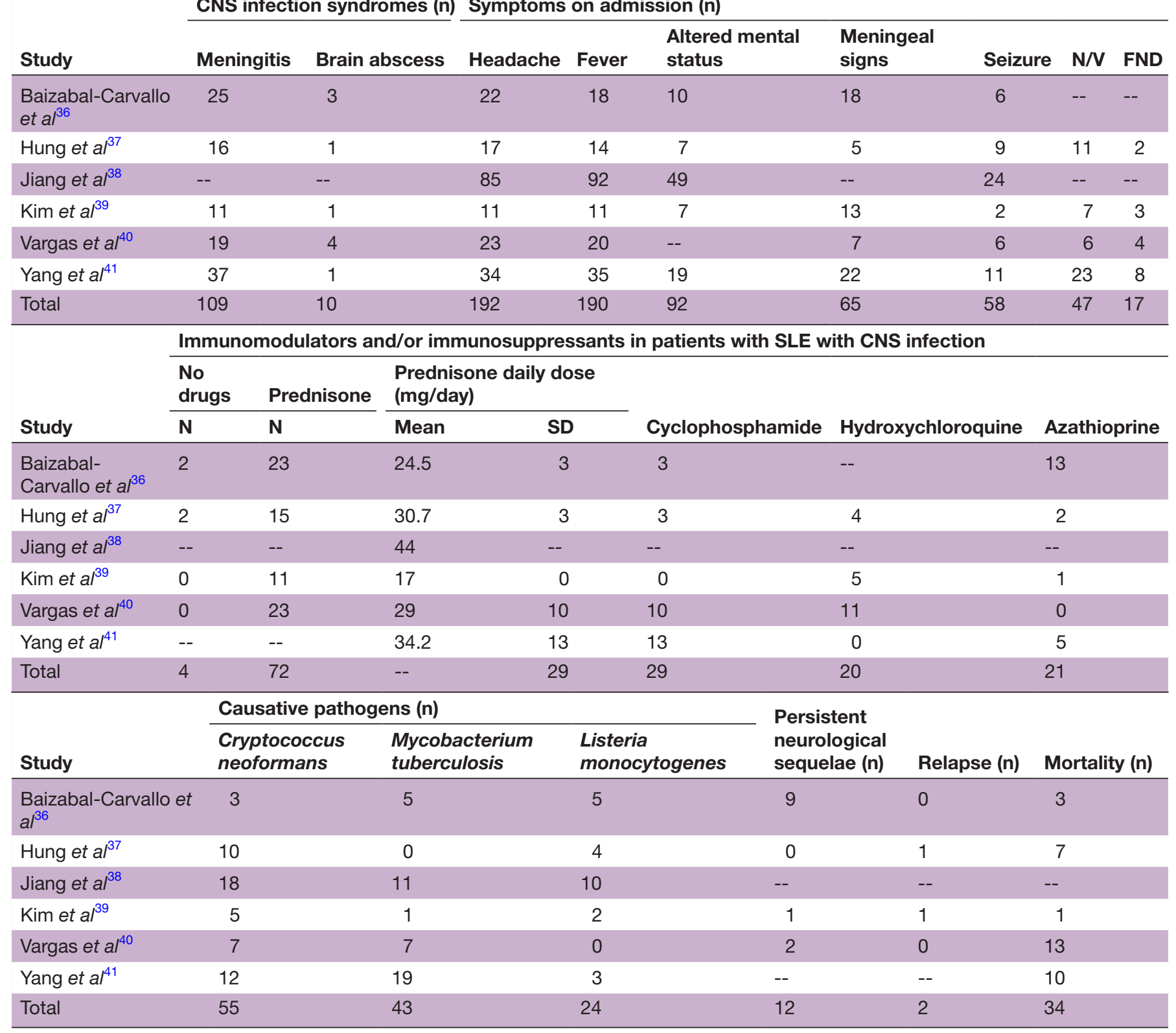

CNS, central nervous system; FND, focal neurological deficits; N/V, nausea or vomiting.

or encephalomyelitis). Funnel plot showed asymmetry for meningitis cases, however, was symmetrical in case of patients with abscess (online supplemental figure S1).

\section{Symptoms on admission}

The most common symptoms on admission were headache $(90.4 \%, \mathrm{n}=192 / 209,95 \% \mathrm{CI}: 85.3 \%$ to $93.8 \%$, $\left.\mathrm{I}^{2}<0.1 \%\right)$ and fever $(89.0 \%, \mathrm{n}=190 / 209,95 \%$ CI: $77.9 \%$ to $\left.94.9 \%, \mathrm{I}^{2} 62.1 \%\right)$, followed by nausea or vomiting $(53.1 \%$, $\mathrm{n}=47 / 89,4$ articles, $95 \%$ CI: $34.5 \%$ to $\left.70.9 \%, \mathrm{I}^{2} 63.5 \%\right)$, meningeal signs $(49.4 \%, \mathrm{n}=58 / 114,5$ articles, $95 \% \mathrm{CI}$ : $33.0 \%$ to $\left.65.9 \%, \mathrm{I}^{2} 65.3 \%\right)$, altered mental status $(49.5 \%$, $\mathrm{n}=92 / 186,5$ articles, $95 \%$ CI: $42.3 \%$ to $\left.56.7 \%, \mathrm{I}^{2}<0.1 \%\right)$, seizure $\left(28.4 \%, \mathrm{n}=58 / 209,95 \% \mathrm{CI}: 21.8 \%\right.$ to $36.0 \%, \mathrm{I}^{2}$ $15.3 \%)$ and focal neurological deficits $(19.5 \%, \mathrm{n}=17 / 89$,
4 articles, $95 \%$ CI: $12.5 \%$ to $29.3 \%, \mathrm{I}^{2}<0.1$ ), including paraparesis, hemiparesis, cranial nerve palsy, diplopia or blurred vision (online supplemental figure S2). Funnel plots are available in online supplemental figure S1.

\section{Medications}

Seventy-two out of 76 cases $(92.4 \%, \mathrm{n}=72 / 76,4$ articles, $95 \%$ CI: $83.0 \%$ to $96.8 \%, \mathrm{I}^{2}<0.1 \%$ ) were taking oral corticosteroids, with a mean daily dose of $30.9 \mathrm{mg} /$ day (4 articles, $95 \%$ CI: 18.0 to $43.7, \mathrm{I}^{2} 94.3 \%$ ) prednisone (table 2 ). All six studies provided a mean daily corticosteroid dose of their subjects; however, two studies did not report the SD of their results and two major studies (Jiang et al and Yang et $a l$ ) did not report the exact number of cases on corticosteroids and were consequently omitted from the analysis by the software. Other immunomodulators or 
immunosuppressants included CYC $(24.5 \%, \mathrm{n}=29 / 114$, 5 articles, $95 \%$ CI: $13.2 \%$ to $40.9 \%$ I $^{2} 57.3 \%$ ), hydroxychloroquine (20.4\%, n=20/114, 5 articles, $95 \%$ CI: $6.8 \%$ to $\left.47.3 \%, \mathrm{I}^{2} 73.8 \%\right)$, AZA $(15.3 \%, \mathrm{n}=21 / 114,5$ articles, $95 \%$ CI: $4.8 \%$ to $\left.39.5 \%, \mathrm{I}^{2} 77.6 \%\right)$, MMF $(6.9 \%, \mathrm{n}=5 / 114$, 5 articles, $95 \%$ CI: $2.9 \%$ to $15.3 \%, \mathrm{I}^{2} 8.7$ ) and MTX (5.6\%, $\mathrm{n}=4 / 114,5$ articles, $95 \%$ CI: $1.8 \%$ to $\left.16.3 \%, \mathrm{I}^{2} 29.2 \%\right)$. Four of 76 cases $(7.6 \%, \mathrm{n}=4 / 76,4$ articles, $95 \%$ CI: $3.2 \%$ to $17.0 \%, \mathrm{I}^{2}<0.1 \%$ ) were not taking any immunosuppressive medication, and Jiang et al did not report the exact number of cases on each individual drug (forest plots in online supplemental figure S2 and funnel plots in online supplemental figure S1).

\section{Pathogens}

Causative pathogens were identified in 158 of 209 patients with CNS infections (these cases will be referred to as definite CNS infections). In addition, three patients reported the co-infection of two simultaneous pathogens. Overall, bacteria were the most common microorganisms found in patients with definite CNS infections $(61.3 \%$, $\mathrm{n}=102 / 158,6$ articles, $95 \%$ CI: $50.0 \%$ to $71.6 \%, \mathrm{I}^{2} 35.8 \%$ ), followed by fungi $(36.4 \%, \mathrm{n}=56 / 158,6$ articles, $95 \% \mathrm{CI}$ : $27.9 \%$ to $\left.46.0 \%, \mathrm{I}^{2} 22.6 \%\right)$, viruses $(\mathrm{n}=2)$ and parasites $(\mathrm{n}=1)$. C. neoformans $(35.9 \%, \mathrm{n}=55,6$ articles, 95\% CI: $27.2 \%$ to $45.7 \%, \mathrm{I}^{2} 25.2 \%$ ), M. tuberculosis $(27.1 \%, \mathrm{n}=43,6$ articles, $95 \%$ CI: $14.6 \%$ to $44.8 \%, \mathrm{I}^{2} 69.5 \%$ ), Listeria monocytogenes $(17.4 \%, \mathrm{n}=24,6$ articles, $95 \%$ CI: $10.6 \%$ to $27.2 \%$, $\left.\mathrm{I}^{2} 30.8 \%\right)$, Streptococcus pneumonia $(\mathrm{n}=6)$ and Nocardia asteroides $(n=4)$ were the most common causative agents (forest plots in online supplemental figure S2 and funnel plots in online supplemental figure S1). The pathogens isolated from cases with brain abscess were $C$. neoformans $(\mathrm{n}=3 / 10), M$. tuberculosis $(\mathrm{n}=2 / 10)$ and L. monocytogenes, Haemophilus influenzae, Corynebacterium bovis-Actinomyces viscosus co-infection and Aspergillus fumigatus, each in one patient (one case of unidentified pathogen).

Our pooled analysis showed an interval of 52.0 months ( $\mathrm{n}=114,5$ articles, $95 \%$ CI: 40.2 to $63.7, \mathrm{I}^{2} 61.2 \%$ ) between the diagnosis of SLE and CNS infection. Subgroup analysis showed an interval of 36.6 months ( $\mathrm{n}=23,2$ articles, 95\% CI: 21.0 to $52.2, \mathrm{I}^{2}<0.1 \%$ ) from the diagnosis of SLE to the diagnosis of CNS infection in cryptococcal meningitis $(\mathrm{CM})$, and 47.7 months $(\mathrm{n}=19,1$ article, $95 \%$ CI: 25.0 to $70.4, \mathrm{I}^{2}<0.1 \%$ ) in CNS tuberculosis (CNS $\mathrm{TB}$ ) (figure 3A). This interval was lower in patients with CM compared with all CNS infections (difference in means $=15.1$, 95\% CI: -7.8 to 37.9 ), although not statistically significant $(\mathrm{p}=0.196)$.

The time interval from the onset of symptoms to the diagnosis of CNS infections was 14.2 days $(\mathrm{n}=89,4$ articles, $95 \%$ CI: 11.1 to 17.3 I $^{2} 79.4 \%$ ) for all CNS infections, 13.9 days $\left(\mathrm{n}=23,2\right.$ articles, $95 \%$ CI: 9.5 to $18.3, \mathrm{I}^{2}$ $29.5 \%)$ for CM, 24.2 days ( $\mathrm{n}=19,1$ article, $95 \%$ CI: 15.8 to $\left.32.7, \mathrm{I}^{2}<0.1 \%\right)$ for CNS TB and 6.2 days $(\mathrm{n}=13,2$ articles, $95 \%$ CI: 3.5 to $9.0, \mathrm{I}^{2} 87.1 \%$ ) for other bacterial CNS infections (figure 3B). Our subgroup analysis showed that patients with CM had a higher interval from onset of
A)

Mean time interval from SLE diagnosis to CNS infection

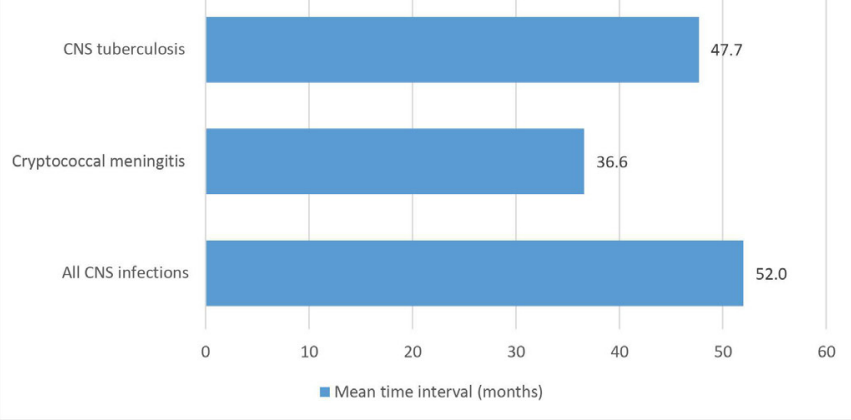

B)

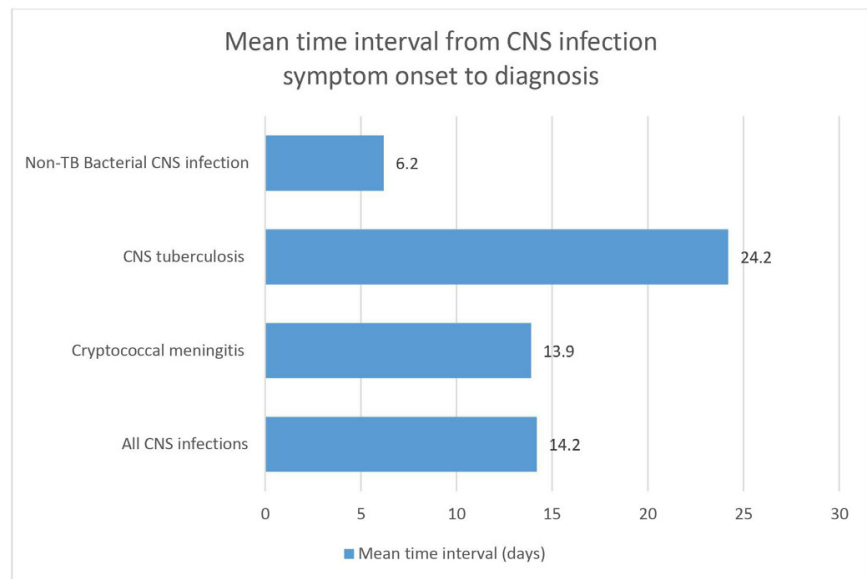

Figure 3 The bar charts show mean time interval (A) from SLE diagnosis to central nervous system (CNS) infection; (B) from CNS infection symptom onset to diagnosis. TB, tuberculosis.

symptoms to diagnosis of CNS infection compared with other non-TB bacterial CNS infections (difference in means 6.7 days, $95 \%$ CI: 0.3 to $\left.13.1, \mathrm{I}^{2} 28.9 \%\right)$.

\section{Mortality \& Morbidity}

Overall, 34 SLE cases with CNS infections died (mortality rate $29.0 \%, \mathrm{n}=34 / 114,31$ meningitis cases and $3 \mathrm{CNS}$ abscess cases, 5 articles, $95 \%$ CI: $15.0 \%$ to $48.6 \%, \mathrm{I}^{2} 69.8 \%$ ) including 9 patients with CNS TB, 9 patients with CM and 3 patients with $L$. monocytogenes. The aetiological diagnosis was not mentioned in other 13 cases who succumbed to death. Of those who died, CNS infection was complicated by cryptococcaemia in 4 patients, cryptococcaemia with Salmonella enteritidis B bacteraemia in one case, and septic shock in two patients (forest plots in online supplemental figure S2 and funnel plots in online supplemental figure S1).

Among survivors, 12 cases $(13.3 \%, \mathrm{n}=12 / 76,4$ articles, 95\% CI: $3.8 \%$ to $37.0 \%, \mathrm{I}^{2}$ 64.4) developed persistent neurological sequelae during the follow-up period. The neurological sequelae were: decreased visual acuity $(n=4)$, unilateral abducens nerve palsy $(n=4)$, hypoacusia $(n=1)$, cognitive impairment $(n=1)$, persistent partial seizures $(\mathrm{n}=1)$, residual facial nerve palsy $(\mathrm{n}=1)$, hypalgesia on the 
left side of the body $(\mathrm{n}=1)$ and residual unilateral hearing loss $(\mathrm{n}=1)$.

Only two cases $(4.7 \%, \mathrm{n}=2 / 76,4$ articles, $95 \%$ CI: $1.5 \%$ to $13.7 \%, \mathrm{I}^{2}<0.1 \%$ ), both diagnosed with $\mathrm{CM}$, experienced a relapse of the CNS infection.

\section{DISCUSSION}

To the best of our knowledge, this is the first systematic review and meta-analysis on CNS infections in patients with SLE. Our results showed a frequency rate of 0.012 (95\% CI: 0.008 to 0.018 ) for CNS infections in patients with SLE. Meningitis was the most common clinical syndrome $(93.5 \%, \mathrm{n}=109 / 114,95 \% \mathrm{CI}: 82.6 \%$ to $97.8 \%)$ and C. neoformans (35.9\%, $\mathrm{n}=55,95 \%$ CI: $27.2 \%$ to $45.7 \%$ ) and $M$. tuberculosis $(27.1 \%, \mathrm{n}=43,95 \%$ CI: $14.6 \%$ to $44.8 \%)$ were the most common causative pathogens among patients with definite CNS infection. Although considerable information exists about defect in humoral immunity of patients with SLE, ${ }^{44}$ encapsulated bacteria accounted for a minority of SLE cases with CNS infections. Most patients $(92.4 \%, \mathrm{n}=72 / 76,95 \%$ CI: $83.0 \%$ to $96.8 \%)$ were on oral systemic corticosteroids, with a prednisone equivalent mean daily dose of $30.9 \mathrm{mg} /$ day (95\% CI: 18.0 to 43.7). The time interval between the diagnosis of SLE and CNS infection was 52.0 months (95\% CI: 40.2 to 63.7 ) and the interval from onset of neurological symptoms to the diagnosis of CNS infection was 14.2 days (95\% CI: 11.1 to $17.3)$. Headache $(90.4 \%, \mathrm{n}=192 / 209,95 \%$ CI: $85.3 \%$ to $93.8 \%)$ and fever $(89.0 \%, \mathrm{n}=190 / 209,95 \%$ CI: $77.9 \%$ to $94.9 \%$ ) were the most common presenting symptoms of CNS infection among patients with SLE. Lupus Disease Activity Index indicated a mean SLEDAI score of 7.9 (95\% CI: 6.1 to 9.6) in our patient pool. Moreover, our meta-analysis revealed a mortality rate of $29.0 \%$ (95\% CI: $15.0 \%$ to $48.6 \%$ ), a persistent neurological sequelae rate of $13.3 \%$ (95\% CI: $3.8 \%$ to $37.0 \%$ ) and a relapse rate of $4.7 \%$ (95\% CI: $1.5 \%$ to $13.7 \%$ ) in patients with SLE with CNS infection.

According to a 2014 systematic review and metaanalysis, CM accounted for the most common invasive fungal infection (IFI) in SLE cases, constituting 79.9\% of fungal CNS infections and $25.8 \%$ of all IFIs. ${ }^{45}$ Another meta-analysis in 2016 reported an overall pooled prevalence of 0.005 (95\% CI: 0.004 to 0.008 , high heterogeneity) for CM among patients with SLE. ${ }^{46}$ Furthermore, both meta-analyses ${ }^{4546}$ showed most patients with CM had active SLE at the time of presentation, and those on a higher daily dose of corticosteroids experienced higher mortality rates. In our meta-analysis, patients with CM had a mean SLEDAI of 5.4 (95\% CI: 2.9 to 7.9 ) and a prednisone equivalent mean daily dose of $29.1 \mathrm{mg}$ (95\% CI: 22.1 to 36.0 ), further validating that active disease status and higher corticosteroid doses can result in an increased risk of CM. Despite the importance of considering CM in patients with SLE with suspected CNS infections, the diagnosis of $\mathrm{CM}$ is often missed or delayed, ${ }^{45} 46$ and fungal diagnostic tests are not requested on cerebrospinal fluid (CSF) obtained from first lumbar puncture. ${ }^{46}$ Our subgroup analysis showed that patients with CM experienced a significant delay in diagnosis compared with other non-TB bacterial CNS infections (difference in means 6.7 days, 95\% CI: 0.3 to $13.1, \mathrm{p}<0.05)$. Thus, it is important for physicians to maintain a high index of suspicion for CM in SLE cases with suspected CNS infection, particularly in those with moderate-to-high SLEDAI and those on high doses of systemic corticosteroids.

Although empiric antimicrobial therapy is recommended for CNS infections, empiric antifungal therapy is not a standard of care, thus, delay in treatment of CM occurs frequently until the diagnosis is confirmed. Furthermore, the unaffordability of antifungals in less developed countries further complicate this issue. ${ }^{45} 46$ While antifungals might be potentially useful empirically in patients with SLE who are suspected to have fungal CNS infections, side effects such as toxicity and high cost of antifungals make decision-making regarding empiric antifungal therapy particularly challenging. Therefore, we suggest employing fungal diagnostic tests that are less time-consuming than cultures, such as blood or CSF tests for detecting cryptococcal antigens, on the initial CSF and blood tests of these patients.

M. tuberculosis was the second most common causative pathogen in patients with SLE with CNS infection (27.1\%, n=43, 95\% CI: $14.6 \%$ to $44.8 \%)$. It accounted for at least $26.5 \%$ of deaths due to CNS infections in patients with SLE. Although increased rates of TB are expected in endemic regions, ${ }^{47}$ the prevalence of TB is higher in SLE cohorts than the general population, ${ }^{42}$ 48-54 especially extrapulmonary forms such as meningitis. ${ }^{48} 49$ A recent meta-analysis has reported that SLE cases are at a substantially higher risk of $\mathrm{TB}$ compared with the general population (pooled risk ratio $=6.11,95 \%$ CI: 3.61 to $10.33, \mathrm{p}<0.05) .^{3}$ Furthermore, higher cumulative and daily doses of prednisone have been associated with an increased risk of TB in SLE. ${ }^{48}{ }^{49-58}$ In fact, corticosteroid use is an independent risk factor for TB-related mortality in patients with SLE ${ }^{59}$ Hydroxychloroquine, on the other hand, has shown some protective effects against major TB infections in patients with SLE (OR=0.13; 95\% CI: 0.04 to 0.36$),{ }^{55} 56$ especially CNS TB. ${ }^{56}$ Novel biological agents such as antitumour necrosis (TNF) factors that are used in the treatment of SLE and other rheumatological disorders significantly increase the risk of TB reactivation in patients with SLE, ${ }^{60-63}$ and screening for and treating latent TB infection is recommended before anti-TNF treatment. ${ }^{60-63}$ In our meta-analysis, all patients with SLE were taking corticosteroids when diagnosed with CNS TB, but no cases were on anti-TNF treatment. Thus, neurotuberculosis should be considered among the most important causes of CNS infections in patients with SLE, particularly in those on higher doses of systemic corticosteroids or anti-TNFs in TB endemic regions or those with other relevant epidemiological factors (such as history of prior TB, known or possible TB exposure). Given suboptimal sensitivity and specificity of TB diagnostic tests, 
definitive diagnosis of CNS TB can be challenging and time consuming. ${ }^{64}{ }^{65}$ Empiric antituberculous treatment should not be delayed, given the high mortality and complication rate of untreated CNS TB. ${ }^{66}{ }^{67}$ Accordingly, we emphasise on the initiation of empiric antituberculous treatment for patients with SLE who are highly suspected to have CNS TB while awaiting the results of diagnostic tests.

The overall mortality rate of patients with SLE with CNS infection was $29.0 \%$ (95\% CI: $15.0 \%$ to $48.6 \%$ ) in our patient pool. CM and CNS TB accounted for more than half of all deaths in patients with SLE with CNS infections. Due to paucity of data in the studies that were included in our meta-analysis, we could not perform subgroup metaanalysis for risk factors of mortality and morbidity. Yang et al identified a higher CSF protein level, a higher mean dose of prednisone received within the last year and a low serum albumin level as predisposing factors for an unfavourable outcome in patients with SLE with CNS infection; defined as death within the first month, vegetative state, conscious but requiring constant supervision, severe or moderate disability, neurological impairment but independent. ${ }^{41}$ Baizabal-Carvallo et al and Hung et al proposed other risk factors for mortality in CNS infection such as septic shock and cryptococcaemia. ${ }^{36}{ }^{37}$ Hydroxychloroquine has been reported as the only proven protective asset against infection-related mortality in patients with SLE. ${ }^{68}$ Despite the potential protective effect, almost only one-fourth of patients with SLE with CNS infection in our review were taking hydroxychloroquine $(20.4 \%$, n=20/114, $95 \%$ CI: $6.8 \%$ to $47.3 \%$ ). Future research on CNS infections in patients with SLE including cohort studies should focus on identifying risk and protective factors for mortality and morbidities.

Our study had several limitations that should be mentioned. First, the included studies in our meta-analysis were mainly from Asia, therefore, the results may not be representative of patients in other regions and the recommendations may be regional in nature due to differences in comorbidities, access to care and lack of preventative approaches. Furthermore, a suboptimal standard of care in the included studies, such as a low frequency of maintenance treatment with hydroxychloroquine and high daily doses of prednisone, which are not in line with current management recommendations, could have influenced the frequency of CNS infections and the main causative agents. Other treatment strategies might lead to different circumstances regarding frequency and main pathogens. Moreover, we were not able to estimate the relative risk of CNS infections and its associated factors given the paucity of available data, including absence of adequate control groups; hence, we could only report a descriptive analysis. Finally, the included studies used different diagnostic criteria for CNS infections, which resulted in substantial heterogeneity among patients. Even though all six articles had used microbiological tests on all of their patients and included patients who were diagnosed by a multidisciplinary panel of experts based on their clinical manifestations, laboratory tests and response to treatment, the reliability of diagnosis of CNS infection without microbiological confirmation is still debatable, especially considering that reported clinical manifestations of CNS infection and CNS lupus can be similar. Importantly, cases where the aetiological agent could not be identified might lead to bias in estimating the frequency of each pathogen. Consequently, we limited our frequency analysis to cases that had a known positive microbiological result, and reported frequency percentages and proportions accordingly.

In conclusion, meningitis is the most frequent clinical syndrome in patients with SLE with CNS infections. C. neoformans, M. tuberculosis and L. monocytogenes were the most common causative pathogens while encapsulated bacteria accounted for a minority of SLE cases with CNS infections. Clinicians should maintain a high index of suspicion for CM and CNS TB in patients with SLE who present with clinical syndromes suggestive of CNS infection, especially those with moderate-to-high SLEDAI and those on higher doses of systemic corticosteroids. The high frequency of C. neoformans as a causative pathogen of CNS infections in patients with SLE suggests that antifungals might be potentially useful empirically in patients with SLE who are highly suspected to have fungal CNS infections; however, side effects such as toxicity and high cost of antifungals make such decision particularly challenging. Performing diagnostic tests that are less time-consuming than cultures, namely blood or CSF cryptococcal antigen tests could be potentially helpful in decision making regarding empiric therapy. We also suggest initiation of empiric antituberculous treatment for patients with SLE who are highly suspected to have CNS TB while awaiting the results of diagnostic tests. We emphasise on employing treatment of latent TB infection after targeted screening of patients who are starting moderate-to-high doses of prednisone and/or other high-risk immunosuppressants. Additionally, treatment regimens for patients with SLE should become optimised with maintenance therapy with hydroxychloroquine and minimisation of high-dose prednisone.

Contributors FS and KM designed the outline of the study and conducted the systematic literature search. KM, FS and AB selected eligible manuscripts, extracted and evaluated the raw data and assessed the quality of the manuscripts. $\mathrm{KM}, \mathrm{AB}$ and NM performed the meta-analysis. All authors aided in interpretation of the data. $\mathrm{KM}$ and FS wrote critical portions of the initial manuscript. All authors contributed to critical revision of the manuscript for important intellectual and scientific content. KM and FS performed the final editing and revision of the manuscript. All authors approved the final work and agreed to be accountable for all aspects of the work.

Funding This research was conducted with funding support from the vicechancellery for research of Mashhad University of Medical Sciences (Research Project Number 951021 and ethic code of IR.MUMS.fm.REC.1396.824).

Competing interests None declared.

Patient consent for publication Not applicable.

Ethics approval This study was approved by the Ethics Committee of Mashhad University of Medical Sciences under the project number 951021 and ethic code of IR.MUMS.fm.REC.1396.824.

Provenance and peer review Not commissioned; externally peer reviewed. 
Supplemental material This content has been supplied by the author(s). It has not been vetted by BMJ Publishing Group Limited (BMJ) and may not have been peer-reviewed. Any opinions or recommendations discussed are solely those of the author(s) and are not endorsed by BMJ. BMJ disclaims all liability and responsibility arising from any reliance placed on the content. Where the content includes any translated material, BMJ does not warrant the accuracy and reliability of the translations (including but not limited to local regulations, clinical guidelines, terminology, drug names and drug dosages), and is not responsible for any error and/or omissions arising from translation and adaptation or otherwise.

Open access This is an open access article distributed in accordance with the Creative Commons Attribution Non Commercial (CC BY-NC 4.0) license, which permits others to distribute, remix, adapt, build upon this work non-commercially, and license their derivative works on different terms, provided the original work is properly cited, appropriate credit is given, any changes made indicated, and the use is non-commercial. See: http://creativecommons.org/licenses/by-nc/4.0/.

\section{ORCID iDs}

Kasra Molooghi http://orcid.org/0000-0002-0761-7092

Fereshte Sheybani http://orcid.org/0000-0002-0766-4286

\section{REFERENCES}

1 Tsokos GC. Systemic lupus erythematosus. N Engl J Med 2011;365:2110-21.

2 Aringer M, Costenbader K, Daikh D, et al. 2019 European League against Rheumatism/American College of rheumatology classification criteria for systemic lupus erythematosus. Ann Rheum Dis 2019;78:1151-9.

3 Pego-Reigosa JM, Nicholson L, Pooley N, et al. The risk of infections in adult patients with systemic lupus erythematosus: systematic review and meta-analysis. Rheumatology 2021;60:60-72.

4 Alur S, Mary Thabah M, Sistla S, et al. Occurrence, predictors and outcome of infections at three months in hospitalized patients with SLE: a prospective study from southern India. Lupus 2020;29:649-58.

5 Tektonidou MG, Wang Z, Dasgupta A, et al. Burden of serious infections in adults with systemic lupus erythematosus: a national population-based study, 1996-2011. Arthritis Care Res 2015;67:1078-85.

6 Alarcón GS, McGwin G, Bastian HM, et al. Systemic lupus erythematosus in three ethnic groups. VII [correction of VIII]. Predictors of early mortality in the LUMINA cohort. LUMINA Study Group. Arthritis Rheum 2001;45:191-202.

7 Tselios K, Gladman DD, Sheane BJ, et al. All-Cause, cause-specific and age-specific standardised mortality ratios of patients with systemic lupus erythematosus in Ontario, Canada over 43 years (1971-2013). Ann Rheum Dis 2019;78:802-6.

8 Cervera R, Khamashta MA, Font J, et al. Morbidity and mortality in systemic lupus erythematosus during a 10-year period: a comparison of early and late manifestations in a cohort of 1,000 patients. Medicine 2003;82:299-308.

9 Fors Nieves CE, Izmirly PM. Mortality in systemic lupus erythematosus: an updated review. Curr Rheumatol Rep 2016;18:21.

10 Tektonidou MG, Lewandowski LB, Hu J, et al. Survival in adults and children with systemic lupus erythematosus: a systematic review and Bayesian meta-analysis of studies from 1950 to 2016. Ann Rheum Dis 2017;76:2009-16.

11 Yurkovich M, Vostretsova K, Chen W, et al. Overall and causespecific mortality in patients with systemic lupus erythematosus: a meta-analysis of observational studies. Arthritis Care Res 2014;66:608-16.

12 Lee YH, Choi SJ, Ji JD, et al. Overall and cause-specific mortality in systemic lupus erythematosus: an updated meta-analysis. Lupus 2016;25:727-34.

13 Petri M, Genovese M. Incidence of and risk factors for hospitalizations in systemic lupus erythematosus: a prospective study of the Hopkins lupus cohort. J Rheumatol 1992;19:1559-65.

14 Feldman CH, Hiraki LT, Winkelmayer WC, et al. Serious infections among adult Medicaid beneficiaries with systemic lupus erythematosus and lupus nephritis. Arthritis Rheumatol 2015;67:1577-85.

15 Goldblatt F, Chambers S, Rahman A, et al. Serious infections in British patients with systemic lupus erythematosus: hospitalisations and mortality. Lupus 2009;18:682-9.

16 Lee J, Dhillon N, Pope J. All-Cause hospitalizations in systemic lupus erythematosus from a large Canadian referral centre. Rheumatology 2013;52:905-9.
17 Dhital R, Pandey RK, Poudel DR, et al. All-Cause hospitalizations and mortality in systemic lupus erythematosus in the US: results from a national inpatient database. Rheumatol Int 2020;40:393-7.

18 Anastasiou C, Trupin L, Glidden DV, et al. Mortality among hospitalized individuals with systemic lupus erythematosus in the US between 2006 and 2016. Arthritis Care Res 2021;73:1444-50.

19 Selvananda S, Chong YY, Thundyil RJ. Disease activity and damage in hospitalized lupus patients: a Sabah perspective. Lupus 2020;29:344-50.

20 Wu X-Y, Yang M, Xie Y-S, et al. Causes of death in hospitalized patients with systemic lupus erythematosus: a 10-year multicenter nationwide Chinese cohort. Clin Rheumatol 2019;38:107-15.

21 Grammatikos AP, Tsokos GC. Immunodeficiency and autoimmunity: lessons from systemic lupus erythematosus. Trends $\mathrm{Mol}$ Med 2012;18:101-8.

22 Barber MRW, Clarke AE. Systemic lupus erythematosus and risk of infection. Expert Rev Clin Immunol 2020;16:527-38.

23 Alarcón GS. Infections in systemic connective tissue diseases: systemic lupus erythematosus, scleroderma, and polymyositis/ dermatomyositis. Infect Dis Clin North Am 2006;20:849-75.

24 Thigpen MC, Whitney CG, Messonnier NE, et al. Bacterial meningitis in the United States, 1998-2007. N Engl J Med 2011;364:2016-25.

25 Rúa-Figueroa Î́nigo, López-Longo J, Galindo-Izquierdo M, et al. Incidence, associated factors and clinical impact of severe infections in a large, multicentric cohort of patients with systemic lupus erythematosus. Semin Arthritis Rheum 2017;47:38-45.

26 Edwards CJ, Lian TY, Badsha $\mathrm{H}$, et al. Hospitalization of individuals with systemic lupus erythematosus: characteristics and predictors of outcome. Lupus 2003;12:672-6.

27 Fang H, Lan L, Qu Y, et al. Differences between central nervous system infection and neuropsychiatric systemic lupus erythematosus in patients with systemic lupus erythematosus. $J$ Int Med Res 2018;46:485-91.

28 Chen J, Feng $\mathrm{X}$, Wang $\mathrm{H}$, et al. Discriminating infectious meningitis versus neuropsychiatric involvement in patients with systemic lupus erythematosus: a single-center experience. Clin Rheumatol 2015;34:365-9.

29 Page MJ, McKenzie JE, Bossuyt PM, et al. The PRISMA 2020 statement: an updated guideline for reporting systematic reviews. BMJ 2021;372:n71.

30 Stroup DF, Berlin JA, Morton SC, et al. Meta-Analysis of observational studies in epidemiology: a proposal for reporting. meta-analysis of observational studies in epidemiology (moose) group. JAMA 2000;283:2008-12.

31 Bombardier C, Gladman DD, Urowitz MB, et al. Derivation of the sledai. A disease activity index for lupus patients. Arthritis \& Rheumatism 1992;35:630-40.

32 Gladman D, Ginzler E, Goldsmith C, et al. The development and initial validation of the systemic lupus international collaborating Clinics/American College of rheumatology damage index for systemic lupus erythematosus. Arthritis Rheum 1996;39:363-9.

33 Wells G, Shea B, O'Connell D. The Newcastle-Ottawa scale (NOS) for assessing the quality of Non-Randomized studies in metaanalysis 2000.

34 Egger M, Davey Smith G, Schneider M, et al. Bias in meta-analysis detected by a simple, graphical test. BMJ 1997;315:629-34.

35 Sterne JAC, Sutton AJ, loannidis JPA, et al. Recommendations for examining and interpreting funnel plot asymmetry in meta-analyses of randomised controlled trials. BMJ 2011;343:d4002.

36 Baizabal-Carvallo JF, Delgadillo-Márquez G, Estañol B, et al. Clinical characteristics and outcomes of the meningitides in systemic lupus erythematosus. Eur Neurol 2009;61:143-8.

37 Hung J-J, Ou L-S, Lee W-I, et al. Central nervous system infections in patients with systemic lupus erythematosus. $J$ Rheumatol 2005;32:40-3.

38 Jiang M, Shi X, Gao X, et al. Clinical features of central nervous system infections and experience in differential diagnosis from neuropsychiatric lupus erythematosus in a cohort of 8491 patients with systemic lupus erythematosus. Arthritis Res Ther 2019;21:189-89.

$39 \mathrm{Kim}$ J-M, Kim K-J, Yoon H-S, et al. Meningitis in Korean patients with systemic lupus erythematosus: analysis of demographics, clinical features and outcomes; experience from affiliated hospitals of the Catholic University of Korea. Lupus 2011;20:531-6.

40 Vargas PJ, King G, Navarra SV. Central nervous system infections in Filipino patients with systemic lupus erythematosus. Int $J$ Rheum Dis 2009;12:234-8.

41 Yang C-D, Wang X-D, Ye S, et al. Clinical features, prognostic and risk factors of central nervous system infections in patients with systemic lupus erythematosus. Clin Rheumatol 2007;26:895-901. 
$42 \mathrm{Xu} \mathrm{Y,} \mathrm{Xu} \mathrm{D,} \mathrm{Zhang} \mathrm{T,} \mathrm{et} \mathrm{al.} \mathrm{The} \mathrm{prevalence} \mathrm{and} \mathrm{clinical} \mathrm{characteristics}$ of systemic lupus erythematosus with infectious brain lesions in China. Scand J Rheumatol 2012;41:466-71.

43 Tan EM, Cohen AS, Fries JF, et al. The 1982 revised criteria for the classification of systemic lupus erythematosus. Arthritis Rheum 1982;25:1271-7.

44 Sawada T, Fujimori D, Yamamoto Y. Systemic lupus erythematosus and immunodeficiency. Immunol Med 2019;42:1-9.

45 Wang LR, Barber CE, Johnson AS, et al. Invasive fungal disease in systemic lupus erythematosus: a systematic review of disease characteristics, risk factors, and prognosis. Semin Arthritis Rheum 2014;44:325-30.

46 Fang W, Chen M, Liu J, et al. Cryptococcal meningitis in systemic lupus erythematosus patients: pooled analysis and systematic review. Emerg Microbes Infect 2016;5:1-7.

47 World Health Organization. Global tuberculosis report 2020, 2020. Available: https://www.who.int/publications///item/9789240013131

48 Xiao X, Da G, Xie X, et al. Tuberculosis in patients with systemic lupus erythematosus-a 37-year longitudinal survey-based study. $J$ Intern Med 2021;290:101-115.

49 Sayarlioglu M, Inanc M, Kamali S, et al. Tuberculosis in Turkish patients with systemic lupus erythematosus: increased frequency of extrapulmonary localization. Lupus 2004:13:274-8.

50 Tam L-S, Li EK, Wong S-M, et al. Risk factors and clinical features for tuberculosis among patients with systemic lupus erythematosus in Hong Kong. Scand J Rheumatol 2002;31:296-300.

51 Yun JE, Lee SW, Kim TH, et al. The incidence and clinical characteristics of Mycobacterium tuberculosis infection among systemic lupus erythematosus and rheumatoid arthritis patients in Korea. Clin Exp Rheumatol 2002;20:127-32.

52 Yang $\mathrm{Y}$, Thumboo J, Tan $\mathrm{BH}$, et al. The risk of tuberculosis in SLE patients from an Asian tertiary hospital. Rheumatol Int 2017;37:1027-33.

53 Chu AD, Polesky AH, Bhatia G, et al. Active and latent tuberculosis in patients with systemic lupus erythematosus living in the United States. J Clin Rheumatol 2009;15:226-9.

54 Balbi GGM, Machado-Ribeiro F, Marques CDL, et al. The interplay between tuberculosis and systemic lupus erythematosus. Curr Opin Rheumatol 2018;30:395-402.

55 Ruiz-Irastorza G, Olivares N, Ruiz-Arruza I, et al. Predictors of major infections in systemic lupus erythematosus. Arthritis Res Ther 2009;11:R109.

56 Torres-González P, Romero-Díaz J, Cervera-Hernández ME, et al. Tuberculosis and systemic lupus erythematosus: a case-control study in Mexico City. Clin Rheumatol 2018;37:2095-102.
57 Yang S-C, Lai Y-Y, Huang M-C, et al. Corticosteroid dose and the risk of opportunistic infection in a national systemic lupus erythematosus cohort. Lupus 2018;27:1819-27.

58 González-Naranjo LA, Coral-Enríquez JA, Restrepo-Escobar M, et al. Factors associated with active tuberculosis in Colombian patients with systemic lupus erythematosus: a case-control study. Clin Rheumatol 2021;40:181-91.

59 Cheng CF, Huang YM, Lu CH, et al. Prednisolone dose during treatment of tuberculosis might be a risk factor for mortality in patients with systemic lupus erythematosus: a hospital-based cohort study. Lupus 2019;28:1699-704.

60 Cantini F, Lubrano E, Marchesoni A, et al. Latent tuberculosis infection detection and active tuberculosis prevention in patients receiving anti-TNF therapy: an Italian nationwide survey. Int $J$ Rheum Dis 2016;19:799-805.

61 Cantini F, Nannini C, Niccoli L, et al. Guidance for the management of patients with latent tuberculosis infection requiring biologic therapy in rheumatology and dermatology clinical practice. Autoimmun Rev 2015;14:503-9.

62 Shobha V, Chandrashekara S, Rao V, et al. Biologics and risk of tuberculosis in autoimmune rheumatic diseases: a real-world clinical experience from India. Int J Rheum Dis 2019;22:280-7.

63 Garziera G, Morsch ALB, Otesbelgue F, et al. Latent tuberculosis infection and tuberculosis in patients with rheumatic diseases treated with anti-tumor necrosis factor agents. Clin Rheumatol 2017;36:1891-6.

64 Basu Roy R, Thee S, Blázquez-Gamero D, et al. Performance of immune-based and microbiological tests in children with tuberculosis meningitis in Europe: a multicentre paediatric tuberculosis network European trials Group (ptbnet) study. Eur Respir J 2020;56. doi:10.1183/13993003.02004-2019. [Epub ahead of print: 0207 2020].

65 Bourgi K, Fiske C, Sterling TR. Tuberculosis meningitis. Curr Infect Dis Rep 2017;19:39.

66 Leonard JM, Schlossberg D. Central nervous system tuberculosis. Microbiol Spectr 2017;5:5.2.11.

67 Garg RK. Central nervous system tuberculosis: Treatment and prognosis. In: UpToDate. Post TW. Waltham, MA: UpToDate, 2021.

68 Teh CL, Wan SA, Ling GR. Severe infections in systemic lupus erythematosus: disease pattern and predictors of infection-related mortality. Clin Rheumatol 2018;37:2081-6.

69 Mok CC, Tse SM, Chan KL, et al. Effect of immunosuppressive therapies on survival of systemic lupus erythematosus: a propensity score analysis of a longitudinal cohort. Lupus 2018;27:722-7. 